\title{
Fear is Stress that causes Weakening of the Immune System
}

\author{
Rhoda L Ross-Williams \\ Independent Author, Advocate and Researcher, USA \\ Correspondence should be addressed to Rhoda LRoss-Williams, rosswilliamsrhoda@gmail.com
}

Received: July 12, 2020; Accepted: July 30, 2020; Published: August 04, 2020

\begin{abstract}
The immune system protects the human body from pathogens like viruses and bacteria. People need to maintain a strong immune system during the COVID-19 pandemic. Unfortunately, the fearmongering news reports on death rates increase fear. This could become a health risk because fear could weaken the immune system by increasing the release of corticosteroid in the body. Modern medicine includes the mind, body, and soul strengthening the immune system.
\end{abstract}

\section{KEYWORDS}

Immune system; COVID-19; Pathogens; Death rates

\section{INTRODUCTION}

The immune system is the body's first line of defense against pathogens like viruses and bacteria so it must be strong. Therefore, people must maintain a strong immune system to minimize their chances of becoming ill from pathogens [1]. The holistic well-being of people results from their response to stressors inclusive of fear [2]. This is because stress triggers the adrenaline glands to release corticosteroids (CSs). CSs is a natural steroid in the human body that could weaken the immune system when the levels are too high. Therefore, high levels of fear could lower the immune system. It is necessary that medical professionals inform their patients that fear increases the probability of people becoming sick during an epidemic. In wake of the current COVID-19 epidemic, this article will provide a simple explanation to all readers of how fear weakens the immune system and how to reduce fear.

\section{NUEROLOGICAL RESPONSE TO FEAR}

Fear is a state of mind that causes many different types of fast and slow deaths. What we see and hear processes through our brain stimulating it to send messages to many neurons at once through the body [3]. Therefore, people reactions to stimulants cause their neurological system to activate the endocrine system's adrenaline glands [4]. Since this is our brain telling our body how to survive our perception will affect the amount of corticosteroids release into the body. Hence, people's perception could cause too much CSs release by the endocrine system [1]. This is why our mindset impacts our health.

The statement mind over matter is more than a figure of speech. This is because our minds establish our body chemistry that affect our health can positively or negatively [5]. Fear is a silent killer many medical professionals need to address. It is known adrenaline

Citation: Rhoda L Ross-Williams, Fear is Stress that causes Weakening of the Immune System. J Clin Cases Rep 3(S4): 19-21. 
glands release CSs that can weaken the immune system [4]. The reason CSs weakens the immune system is because its primary function is to adapt frominternal and external stressors to keep the body safe [4]. Fear mongering news stories during a healthcare crisis means people are more prone for CSs to weaken their immune systems. Therefore, this increases the infection rate of pathogens. This is why it is important that all information released to the public during a pandemic health cris is is accurate and factual.

There is a vast difference between information and propaganda. Health care organizations need to inform people of the affect fear has on the immune system. Therefore, constant misinformation that increases fear during a pandemic healthcare crisis could increase the infection rates. People need to understand fear could weaken their immune systems because the endocrine system releases CSs when there is stress [5]. Therefore, this article establishes the connection between psychological health and physical health.

\section{FEAR IS A MINDSET}

The mindset of each individual determines if the body reacts to a situation as fear. This is why during a pandemic medical professionals should encourage their patients to relax. Therefore, a holistic approach to a public health crisis should be relaxation not fearmongering propaganda. The mainstream media (MSM) could reduce fear by sharing infection rates and survival rates instead of constant death rates headlines. People become fearful during a pandemic lowering their immune system if death is the only topic they hear on MSM.
Therefore, people should keep a fearless positive mindset. The medical professions agree people become healthier by reducing internal and external stressors [5]. Therefore, during these dark times, spirituality or relaxation (chilling out) is the best way to reduce individual's fear. This means a religious person may read scripture, pray, or sing songs of worship. However, none spiritual person may listen to their favorite song, watch a movie, bake, clean, paint, or indulge in their hobby

No matter the relaxation, mechanism of choice creating a fearless mindset that does not weaken the immune system. Medical professionals want people to have strong immune systems. Therefore, people need to reduce their fear by spending time in nature [5]. They should not stop living and poison their mind, body, and soul focusing on the death rate news reports that increase their fear. A fearless mindset is medicine for the mind, body, and soul. Since fear weakens the immune system, relaxation is an effective preventive care plan.

\section{CONCLUSION}

The brain stimulates the endocrine system's adrenaline glands when a person is in fear. This causes the body to release corticosteroids (CSs) that weaken the immune system if there is an abnormally high level in the body [3]. Therefore, constant fear mongering could cause CSs levels to become abnormally high. During the $21^{\text {st }}$ century COVID 19 crisis people need to keep a calm mindset. In conclusion, fear is a mindset that can weaken the immune system and relaxation (chilling out) can make the immune systemstronger.

\section{REFERENCES}

1. Gangestad SW, Grebe NM (2014) Pathogen avoidance within an integrated immune system: Multiple components with distinct costs and benefits. Evolutionary Behavioral Sciences 8(4): 226-234.

2. Zaitseva NV, Kiryanov DA, Lanin DV, et al. (2014) A mathematical model of the immune and neuroendocrine systems mutual regulation under the technogenic chemical factors impact. Computational and Mathematical Methods in Medicine 2014: 1-12. 
http://www.tridhascholars.org | December-2020

3. LeDoux JE, Pine DS (2016) Using neuroscience to help understand fear and anxiety: A two-system framework. American Journal of Psychiatry 173: 1083-1093.

4. Ball CM, Featherstone PJ (2017) The early history of adrenaline. Anaesthesia and Intensive Care 45(3): $279-281$.

5. Hart J (2019) The impact of fear and how mindfulness can help. Alternative and Complementary Therapies 25(3): 160162. 